\title{
Application of Monte Carlo Simulation in Treatment Planning for Radiation Oncology
}

\author{
Kin Chan, Soo Min Heng and Robert Smee \\ Radiation Oncology Department, Prince of Wales Hospital \\ Australia
}

\section{Introduction}

In radiotherapy, the dose delivered to patients needs to be determined before the treatment. Therefore, it is necessary to have an accurate method for predicting the dose distribution. In the past, planning computers calculate radiation dose using data obtained by measurement in a water phantom. This will lead to about $3 \%$ to $10 \%$ error in the situations where inhomogeneity and lateral electron disequilibrium occur, especially in small field sizes (Jones AO \& Das IJ, 2005). For these situations, Monte Carlo Simulation (MCS) has been proposed to give the most accurate solution. The first available MCS code for treatment planning was developed as part of the OMEGA project, which started in the early 90s by the National Research Council of Canada and the University of Wisconsin in Madison. The MCS code used was called EGS4 and it modelled the transport of photons and electrons. For radiotherapy, the BEAM system (which was based on EGS4) was used for modelling of radiotherapy sources. These days, EGS4 and BEAM have been replaced by EGSnrc and BEAMnrc.

MCS models the transport of photon and electron by recording the interactions of each particle until it reaches the preset threshold energy. Therefore, MCS requires an extensive use of computer power. In the early 90 s when the processing speed of computers was slow, one simulation would require several days before a result was available. The time required was impractical for clinical purposes. As an alternative, the Convolution algorithm was developed for treatment planning. It calculates the dose delivered to a volume by convolving the interaction sites with the dose deposition kernel derived from the output spectrum of the linear accelerator. The dose deposition kernel is pre-calculated by MCS. Convolution algorithm has improved dose calculation accuracy but it still has limitation compared to real MCS. For example, convolution algorithm uses density scaling to correct for tissue inhomogeneity. This method breaks down in situation where there is a high atomic number material present, e.g. a steel prosthesis. Nowadays, the speed of the computers has increased and parallel processing is more popular. Therefore, it is now feasible to use MCS for treatment planning. Computer Medical System (CMS) has launched a commercial product called Monaco which uses a fast computer and variance reduction techniques to speed up the MCS calculation for radiotherapy treatment planning.

MCS can also be used as a quality assurance (QA) tool for other MCS treatment planning systems. It is possible to do so because each MCS utilises a different coding and variance reduction technique therefore each calculation is considered independent.

All the work in this chapter is accomplished with a free Monte Carlo Software called MCBEAM which is developed by Fox Chase Cancer Care Centre. MCBEAM originates from 
BEAM code with some modifications - it provides an interface with RTOG (Radiation Therapy Oncology Group) protocol so that parameters such as monitor units, field size etc can be imported from the treatment planning system (TPS). MCBEAM implements the multiple source model, as shown in figure 1, as an alternative to the traditional phase space file method. The Multiple source model suggests that a photon beam generated by a linac can be broken down into multiple smaller photon sources that are generated under the flattening filter at different magnitude (shown as arrows in figure 1). The magnitude of each individual source is adjusted so that the sum of all sources matches the data obtained by actual measurement. In order to model the beam correctly, the presence of the jaws ( $x, y$ and/or multi-leaf collimator) have to be entered correctly into the model. The details of the multiple source method can be found in the reference (Fippel $\mathrm{M}$ et al., 2003). The advantages of the multiple source model over the phase space file method are summarised as follow:

1. Smaller file size. The phase space file size is around a few giga-bytes depending on the number of particles stored. The multiple source file size is only a few kilo-bytes.

2. The multiple source model can simulate unlimited number of particles until it reaches the limit set by EGS4 while the phase space file method must recycle the particles, which might affect the accuracy of the result.

3. The multiple source model does not depend on the dimension of each component in the linear accelerator. This makes the machine modelling process easier.

Target
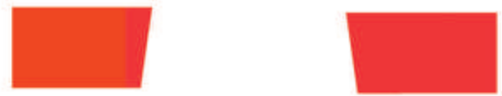

Primary

Collimator

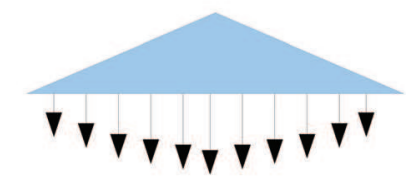

Flattening

Filter

Multiple Source
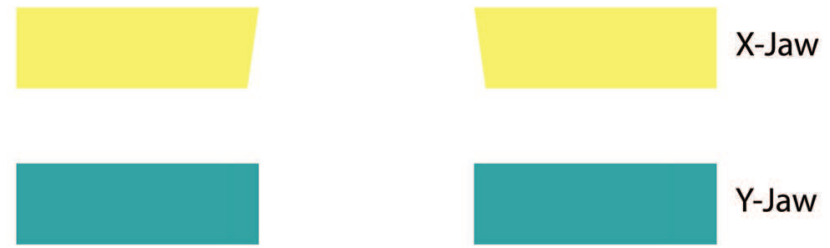

Fig. 1. Diagram of multiple source model

The MCBEAM implements variance reduction techniques to speed up the simulation. These variance reduction techniques can be turned on or off by the user. The techniques used in this work are the photon interaction forcing technique and the electron track repeating technique (Ma CM et al., 2004). From the experience of our department, a treatment plan simulation can be completed within 4 hours. 


\section{Verification of Monte Carlo Simulation with ion chamber measurement}

Some articles have proven that MCS works well under the situation of electron disequilibrium (Ellen W et al., 2008), therefore the MCS results are compared with measurements in a full scatter condition. i.e. in a water phantom, using a field size that is large enough to provide electronic equilibrium to the detector. In our case, the smallest field size measured is $1 \mathrm{~cm} x$ $1 \mathrm{~cm}$. The Scanditronix CC04 and CC01 ion chambers were used in this work.

\subsection{Comparison of Percentage Depth Dose (PDD) with Monte Carlo Simulation and ion chamber measurements}

Figure 2 shows the PDD comparison results for ion chamber measurements and MCS for field sizes from $1 \mathrm{~cm} \times 1 \mathrm{~cm}$ to $10 \mathrm{~cm} \times 10 \mathrm{~cm}$. The differences between measured data and MCS data

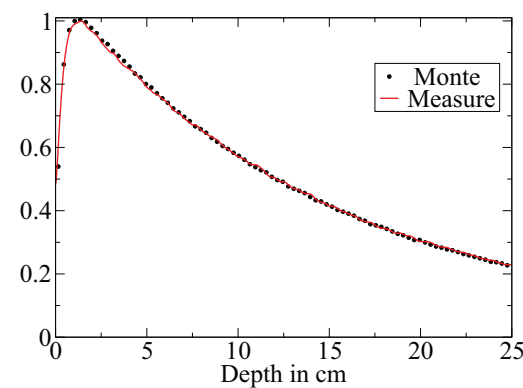

(a) PDD for $1 \times 1 \mathrm{~cm}$

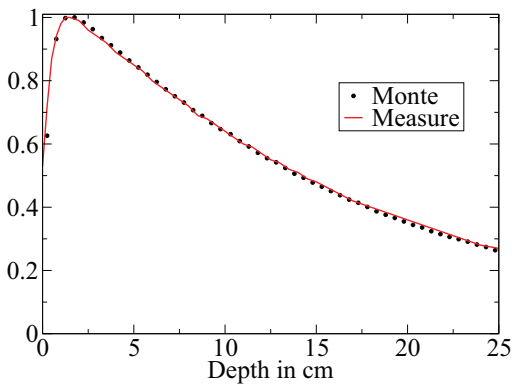

(c) PDD for $5 \times 5 \mathrm{~cm}$

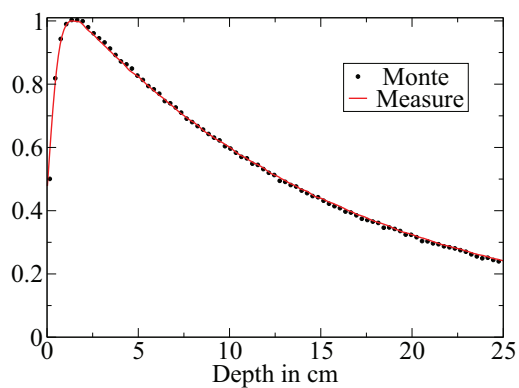

(b) PDD for $2 \times 2 \mathrm{~cm}$

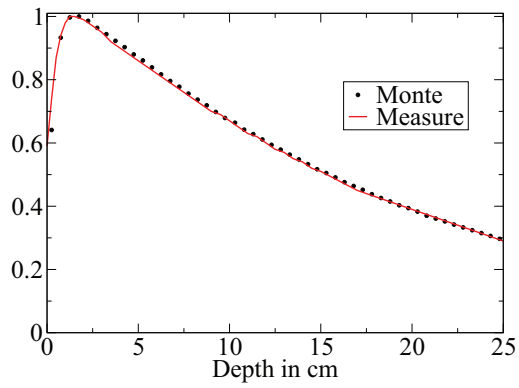

(d) PDD for $10 \times 10 \mathrm{~cm}$

Fig. 2. PDDs comparison for field sizes from $1 \times 1 \mathrm{~cm}$ to $10 \times 10 \mathrm{~cm}$

from depth $1.5 \mathrm{~cm}$ to $25 \mathrm{~cm}$ are less than $2 \%$. In order to make a fair comparison between ion chamber and MCS, the voxel size used in MCS was set to be comparable to the sensitive volume of the ion chamber. This is particularly important especially around the penumbra region due to the volume averaging effect of the ion chamber. 


\subsection{Comparison of profiles between Monte Carlo Simulation and ion chamber measurements}

Figure 3 shows the results for profile comparisons between monte carlo simulations and ion chamber measurements. From Figure $3 a$ to $3 d$, the results match to within $2 \%$ in the low dose gradient region of the profiles (within $80 \%$ of the field width) and match to within $1 \mathrm{~mm}$ in the penumbra region $(90 \%$ to $10 \%$ at the edge). The MCS is shown to accurately predict the round off in the shoulder region for small field sizes, e.g. for $2 \times 2 \mathrm{~cm}$ and $1 \times 1 \mathrm{~cm}$. The profiles are compared at 3 depths, dmax $(1.5 \mathrm{~cm}$ for $6 \mathrm{MV}$ beam), $10 \mathrm{~cm}$ and $20 \mathrm{~cm}$. They are labelled as dmax, d10 and d20 in figure 3. The measured data and the MCS results were labelled as "Mea" and "Monte" respectively. At the time of writing, only the $6 \mathrm{MV}$ photon of a Siemens Oncor linear accelerator has been modelled. Future works will involve modelling other photon energies.

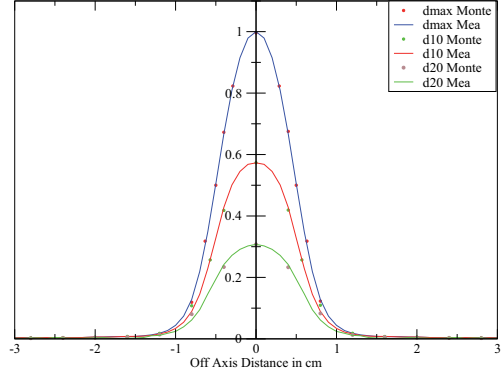

(a) Profiles for $1 \times 1 \mathrm{~cm}$

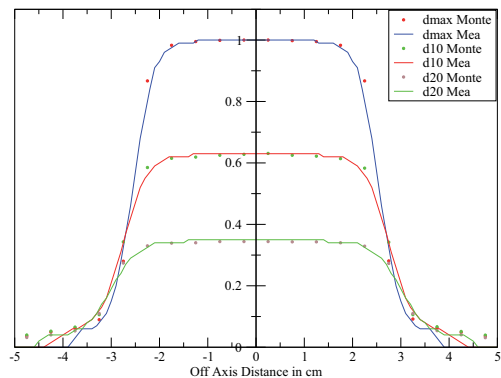

(c) Profiles for $5 \times 5 \mathrm{~cm}$

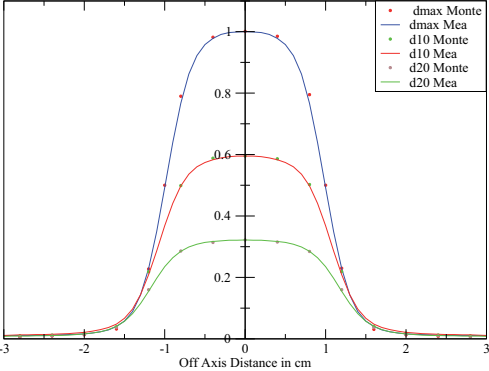

(b) Profiles for $2 \times 2 \mathrm{~cm}$

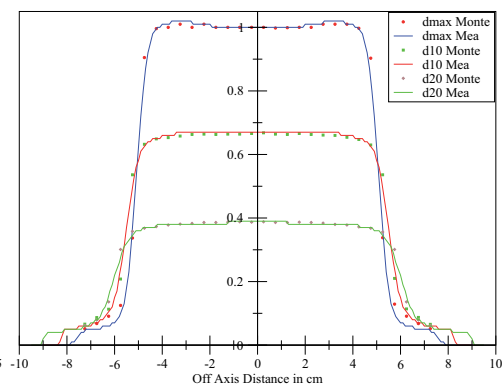

(d) Profiles for $10 \times 10 \mathrm{~cm}$

Fig. 3. PDDs comparison from field size $1 \times 1 \mathrm{~cm}$ to $10 \times 10 \mathrm{~cm}$

\subsection{Comparison of output factors between Monte Carlo Simulation and ion chamber measurements}

Output factor is defined as the ratio of a reading taken for a selected field size at dmax to the reading taken for the reference field size (usually $10 \times 10 \mathrm{~cm}$ ) at dmax. Therefore, MCS has to be performed for both field sizes at dmax, and the output factor is calculated by taking the ratio of the two as shown in equation 1.

$$
\text { Output factor }(F S)=\frac{\operatorname{Result}(F S)}{\operatorname{Result}(\operatorname{Ref})}
$$


Result(FS): Monte Carlo Simulation result for Field Size selected

Result(Ref): Monte Carlo Simulation result for Reference Field Size (10x10cm)

All parameters, except for the field size, have to be kept constant for both simulations. Table 1 shows the results for a Siemens Oncor machine. The measured data agreed with MCS to within $1 \%$ for all field size up to $30 \mathrm{~cm} \times 30 \mathrm{~cm}$ except for field size of $2 \mathrm{~cm} \times 2 \mathrm{~cm}$ which is $1.13 \%$.

\begin{tabular}{|c|c|c|c|}
\hline Field size,cm & MCS & Measurement & Difference, $\%$ \\
\hline $2 \times 2$ & 0.869 & 0.859 & -1.13 \\
\hline $3 \times 3$ & 0.904 & 0.906 & 0.22 \\
\hline $5 \times 5$ & 0.935 & 0.932 & -0.32 \\
\hline $10 \times 10$ & 1.000 & 1.000 & 0.00 \\
\hline $15 \times 15$ & 1.036 & 1.034 & -0.2 \\
\hline $20 \times 20$ & 1.050 & 1.055 & 0.44 \\
\hline $25 \times 25$ & 1.064 & 1.070 & 0.53 \\
\hline $30 \times 30$ & 1.0815 & 1.079 & -0.24 \\
\hline
\end{tabular}

Table 1. Output factors comparison between monte carlo simulation and measurements

Table 2 shows the results for an elongated fields. This is known as the collimator exchange effect. The collimator exchange effect is caused by the different positions of X- and Y-jaw within the linear accelerator with respect to the flattening filter. The dose contribution from the jaws are therefore different for a A $x$ B field and a B $x$ A field. The magnitude of the collimator exchange effect can be shown in the case of an elongate field. From table 2, it can be shown that the output for $4 \times 40 \mathrm{~cm}$ and $40 \times 4 \mathrm{~cm}$ are 0.976 and 0.958 respectively. Some TPS are not able to model the collimator exchange effect and therefore will result in an error of $1.8 \%$ in this situation. Table 2 shows that the MCS are able to predict the dose to an accuracy of within $1 \%$ for an elongated field.

\begin{tabular}{|c|c|c|c|}
\hline Field size,cm & MCS & Measurement & Difference, $\%$ \\
\hline $4 \times 40$ & 0.976 & 0.976 & -0.04 \\
\hline $40 \times 4$ & 0.956 & 0.958 & 0.18 \\
\hline $30 \times 10$ & 1.027 & 1.024 & -0.27 \\
\hline $10 \times 30$ & 1.039 & 1.034 & -0.46 \\
\hline
\end{tabular}

Table 2. Elongated output factors comparison between monte carlo simulation and measurements

\section{Compare Monte Carlo Simulation with planning computer}

Figure 4 shows the work flow of comparing dose calculation from MCS and the TPS. Firstly, the medical images(such as CT, MRI etc) are transferred into the TPS. A treatment plan will be computed according to the Radiation Oncologist's prescription. After that, the parameters of the treatment plan are sent to MCS via RTOG format. Using the same plan parameters, MCS independently calculates the dose and compares it to the original plan generated by the TPS. If the dose calculated by both MCS and TPS agree, then the treatment commences. Figure 5 shows the DVH comparison for an IMRT patient with Paranasal sinus carcinoma in 2006. The CMS XiO planning system was used and the dose calculation was performed using the Superposition algorithm. Other than the DVH, the isodoes was also compared. Figure 6 


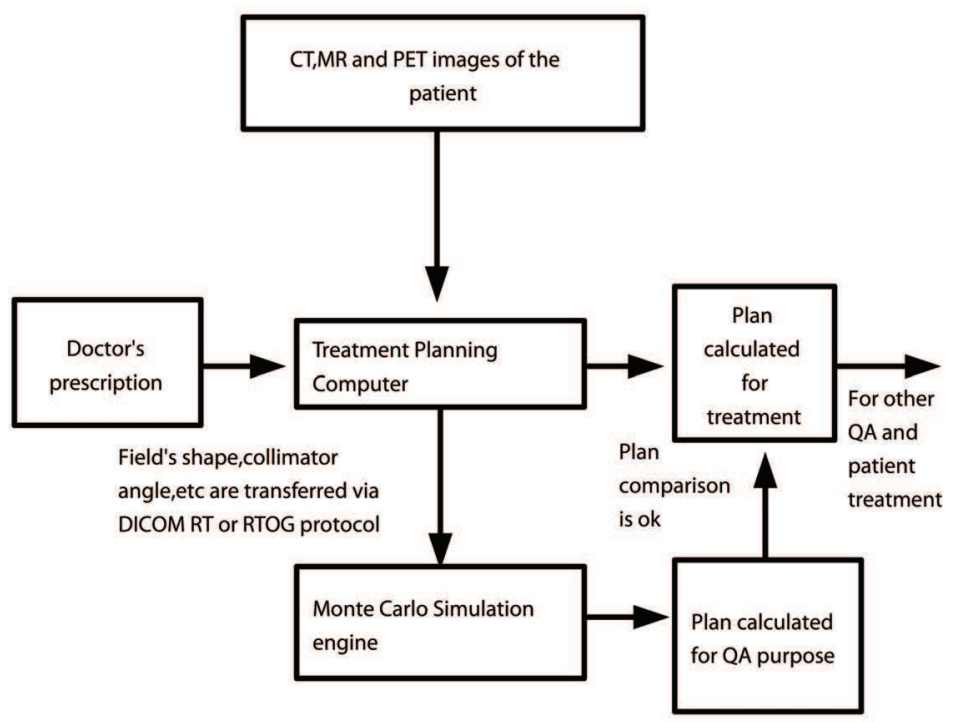

Fig. 4. System diagram for plan comparison between MCS and TPS

DVH comparison

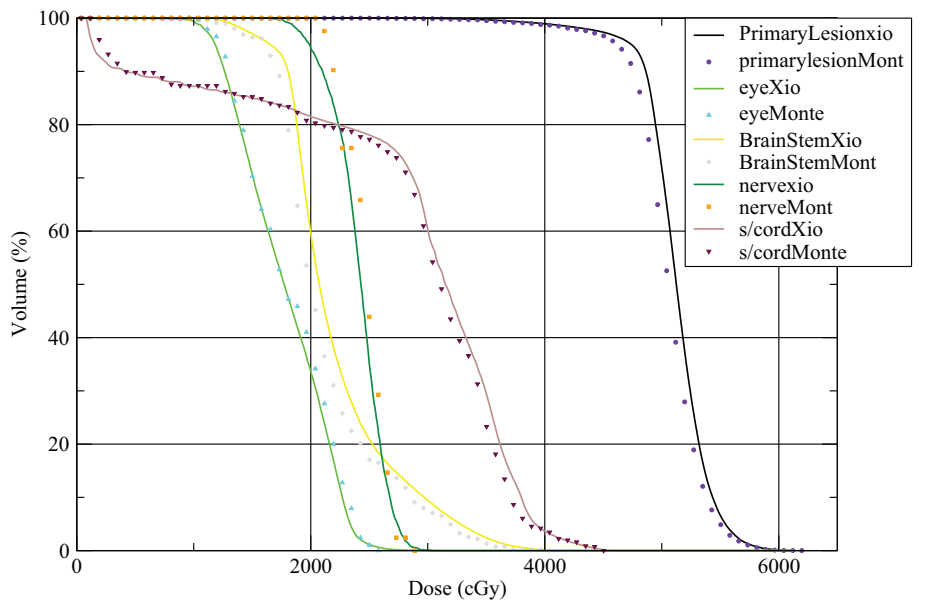

Fig. 5. DVH comparison between MCS and $\mathrm{XiO}$

$\mathrm{a}, \mathrm{b}$ and $\mathrm{c}$ show the isodose comparison for a plan calculated by $\mathrm{XiO}$ in the coronal,sagittal and transverse planes. The left column shows isodoses calculated from $\mathrm{XiO}$ while the right column shows isodoses calculated from MCS. 


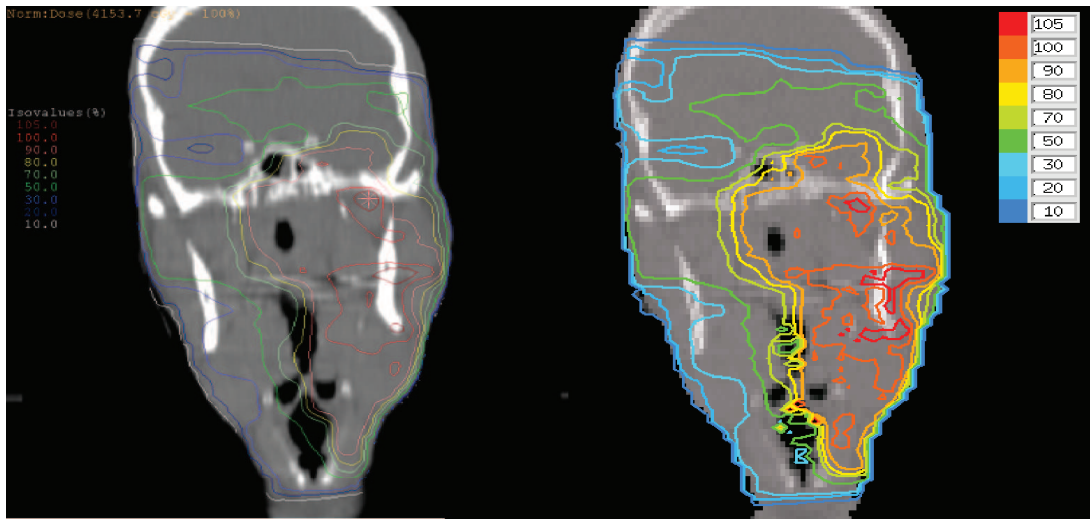

(a) coronal plane

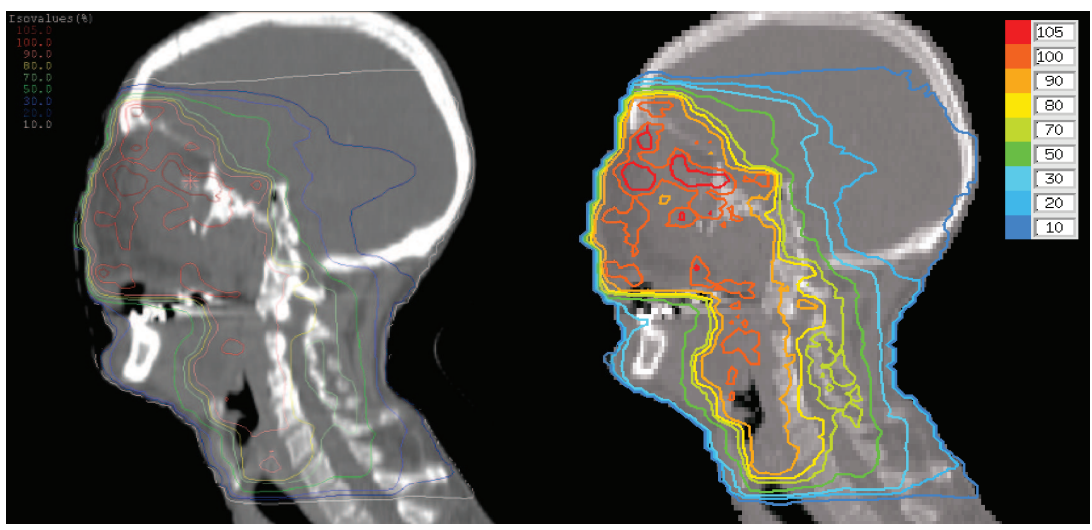

(b) saggital plane

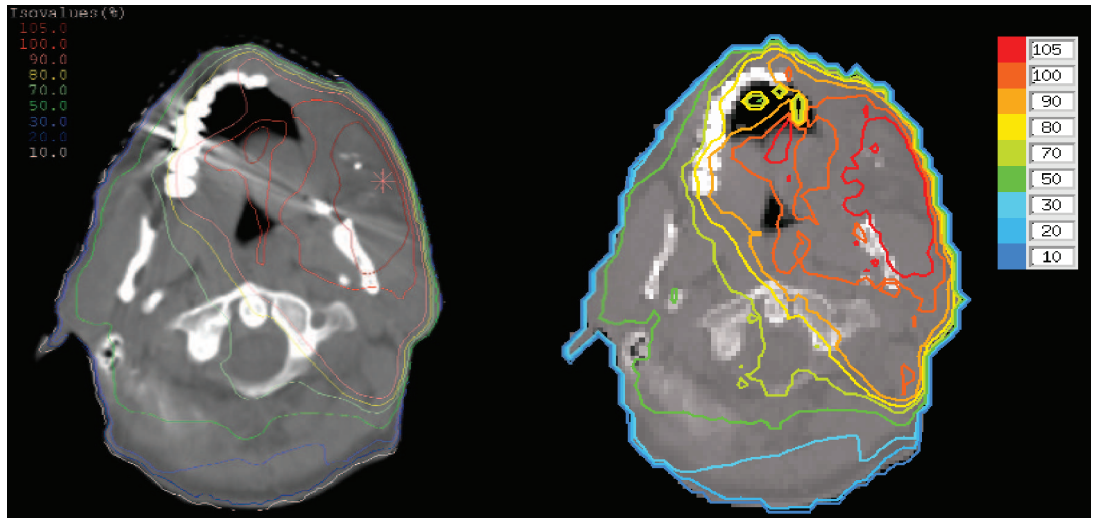

(c) transverse plane

Fig. 6. Isodoses comparison between monte carlo simulation and XiO TPS 


\section{Acknowledgement}

I would like to thank Charlie Ma and Jason Li at the Fox Chase Cancer Centre, Philaphadia, USA for providing the MCBEAM code for this work and Dean Inwood at the Prince of Wales Hosptial, Sydney, Australia for creating the figures 6 used in this chapter.

\section{References}

Jones AO, \& Das IJ. (2005). Comparison of inhomogeneity correction algorithms in small photon fields Med Phys, Vol. 32, pp. 766-276.

Ma C-M, Li JS, Pawlicki T, Jiang SB, Deng J, Lee MC, Koumrian T, Luxton M, rain S (2002). Monte Carlo dose calculation tool for radiotherapy treatment planing. Med Phys, Vol 25, pp. 1671-1689.

Wang L, Chui CS, Lovelock M (1998). A patient-specific Monte Carlo dose-calculation method for photon beams. Med Phys, Vol. 25 pp. 867-878.

Ma CM, Mok E, Kapur A, Pawlicki T, Findley D, Brain S, Forster K, Boyer AL (1999). Clinical implementation of a Monte Carlo treatment planning system Med Phys, Vol 26, pp.2133-2143.

FippelM, Kawrakow I, Friedrich K (2003). A virtual photon energy fluence model for Monte Carlo dose calculatin. Med Phys, Vol.30 pp.301-311.

Seco J, Evans PM. (2006). Assessing the effect of electron density in photon dose calculations.. Med Phys, Vol. 33 pp.540-552.

Schell MC, Bora FC, Larson DA, et al. (1995). AAPM Report No. 54: Stereotactic Radiosurgery. AAPM Task Group 42 Melville, American Institute of Physics

Mayles P, Nahum AE, Rosenwald J-C. (2007)Hand book of Radiotherapy Physics. Oxford, Taylor \& Francis pp. 565-566.

CM Ma, J Li, T Pawlicki, S Jiang Jun Deng. (2004). MCSIM Users Manual. Report No: FCCC-RADPHYS-0201. Department of Radiation Oncology, Fox Chase Cancer Centre, Philadelphia,PA 19111.

Ellen E. Wilcox, George M. Daskalov. (2008). Accuracy of dose measurements and calculations within and beyond heterogeneous tissues for $6 \mathrm{MV}$ photon fields smaller then $4 \mathrm{~cm}$ produced by Cyberknife. Med Phys, Vol 25 pp.2259-2266. 


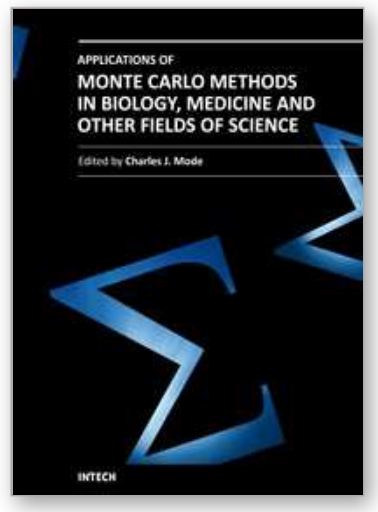

\section{Applications of Monte Carlo Methods in Biology, Medicine and Other Fields of Science}

Edited by Prof. Charles J. Mode

ISBN 978-953-307-427-6

Hard cover, 424 pages

Publisher InTech

Published online 28, February, 2011

Published in print edition February, 2011

This volume is an eclectic mix of applications of Monte Carlo methods in many fields of research should not be surprising, because of the ubiquitous use of these methods in many fields of human endeavor. In an attempt to focus attention on a manageable set of applications, the main thrust of this book is to emphasize applications of Monte Carlo simulation methods in biology and medicine.

\section{How to reference}

In order to correctly reference this scholarly work, feel free to copy and paste the following:

Kin Chan, Soo Min Heng and Robert Smee (2011). Application of Monte Carlo Simulation in Treatment Planning for Radiation Oncology, Applications of Monte Carlo Methods in Biology, Medicine and Other Fields of Science, Prof. Charles J. Mode (Ed.), ISBN: 978-953-307-427-6, InTech, Available from:

http://www.intechopen.com/books/applications-of-monte-carlo-methods-in-biology-medicine-and-other-fieldsof-science/application-of-monte-carlo-simulation-in-treatment-planning-for-radiation-oncology

\section{INTECH}

open science | open minds

\author{
InTech Europe \\ University Campus STeP Ri \\ Slavka Krautzeka 83/A \\ 51000 Rijeka, Croatia \\ Phone: +385 (51) 770447 \\ Fax: +385 (51) 686166 \\ www.intechopen.com
}

\author{
InTech China \\ Unit 405, Office Block, Hotel Equatorial Shanghai \\ No.65, Yan An Road (West), Shanghai, 200040, China \\ 中国上海市延安西路65号上海国际贵都大饭店办公楼 405 单元 \\ Phone: +86-21-62489820 \\ Fax: $+86-21-62489821$
}


(C) 2011 The Author(s). Licensee IntechOpen. This chapter is distributed under the terms of the Creative Commons Attribution-NonCommercialShareAlike-3.0 License, which permits use, distribution and reproduction for non-commercial purposes, provided the original is properly cited and derivative works building on this content are distributed under the same license. 